\title{
PENGEMBANGAN MATERI SEJARAH KEBUDAYAAN ISLAM (SKI) PADA MADRASAH TSANAWIYAH
}

\author{
Isti'anah Abubakar \\ Dosen Jurusan PAI Fakultas Tarbiyah UIN Maliki Malang
}

\begin{abstract}
History as the mother of science indicates the centrality of history as a science that plays an important role in the life and Bohemian. This important position needs to be tranferred through a process of learning, including learning history of Islamic culture. Ironically, history is a unwelcome subject and even almost considered a useless subject. One reason is thar the learning process is still textually. Learning procesess are less developed in balance 3 domain could be due to lack of understanding of the characteristic, the analysis of the material that is not done and learning strategies that are less precise. This paper will discuss the third case, so that the teaching of history is not just storytelling, but also able to present an exciting and meaningful learning. The goal is to position " motherhood" in the scope of scientifiq history.
\end{abstract}

Keyword: history nature, subject analysis

\section{A. Pendahuluan}

Sejarah merupakan ratu atau ibu ilmu ilmu-ilmu sosial. Konotasi ibu dan ratu mengindikasikan bahwa sejarah merupakan ilmu yang yang sangat penting dan tidak boleh disepelekan. Ini terbukti dengan banyaknya pernyataan yang menunjukkan urgensitas sejarah, dimana semua keilmuan pastilah mempunyai sisi historisitasnya. Pemahaman sejarah akan menjadikan pembelajarnya menjadi lebih bijak dan dewasa. Sejarah juga melukiskan pertumbuhan sehingga orang menjadi mengerti masa lalu "sesuatu" yang bermuara pada masa kini. Dengan mengerti masa lalu orang akan memahami masa kini dengan memahami masa kini dapatlah digariskan masa datang. Hal ini dikuatkan dengan tujuan dan fungsi sejarah yang dikatakan 
Ahmad Mansur Suryanegara bahwa, Sejarah mempunyai 3 fungsi yaitu, pertama, dzikra (peringatan ), kedua, mauidhah ( nasehat), dan ketiga, uswah (tauladan). Saratnya makna sejarah inilah yang idealnya mampu ditransferkan kepada generasi penerus.

Ironisnya, sejarah masih asing dan dirasa tidak perlu dipelajari. Kebosanan, ketidakbermanfaatan, kejenuhan merupakan hal-hal yang sangat identik dengan materi sejarah. Beberapa deskripsi terkait hal ini, yaitu : (Mahasiswa IPS, 2010)

a. Research also shows that some pupils consider history to be boring and useless (Schools Council, 1968, Aldrich, 1987, QCA, 2005)

b. who even cares about this, I mean everyone we're studying about is dead anyway. What's the point...?"

c. rendahnya motivasi mahasiswa mengikuti matakuliah SPI Rendahnya motivasi mereka terlihat dengan seringnya mereka tidak mengikuti matakuliah SPI, kalaupun mereka mengikuti matakuliah SPI hanya sebatas pada formalitas tanpa mau bersikap aktif dalam pembelajaran SPI

d. Hasil penelitian mahasiswa terhadap pembelajaran SKI di beberapa Tsanawiyah menunjukkan bahwa pembelajaranSKIbelum dilaksanakan di secara menarik, mengingat mayoritas gurunya "mengaku"terpaksa mengajar SKI, meskipun ada beberapa sekolah yang mampu menghadirkan pembelajaran sejarah yang menarik bagi siswa-siswinya. (Mahasiswa PAI,2012)

Beberapa deskripsi menuntut adanya komitmen untuk mampu menghadirkan sejarah sebagai keilmuan yang berstatus ratu dan ibu, suatu posisi yang harus kita hormati dan kita dahulukan.

Realita di atas menuntut kita untuk mampu menerjemahkan kebermaknaan sejarah yang juga tertuang dalam tujuan mapel PAI dalam hal ini SKI - yaitu : (Kemenag RI, 2010 :14)

a. Membangun kesadaran peserta didik tentang pentingnya mempelajari landasan ajaran, nilai-nilai dan norma-norma Islam yang telah dibangun oleh Rasulullah saw dalam rangka mengembangkan kebudayaan dan peradaban Islam

b. Membangun kesadaran peserta didik tentang pentingnya waktu dan tempat yang merupakan sebuah proses dari masa lampau , 
Isti'anah Abubakar - Pengembangan Materi Sejarah ...

masa kini dan masa depan

c. Melatih daya kritis peserta didik untuk memahami fakta sejarah secara benar dengan didasarkan pendekatan ilmiah

d. Menumbuhkan apresiasi dan penghargaan peserta didik terhadap peninggalan sejarah Islam sebagai bukti peradaban umat Islam di masa lampau

e. Mengembangkan kemampuan peserta didik dalam mengambil ibrah dari persitiwa-peristiwa bersejarah (Islam),meneladani tokoh-tokoh berprestasi dan mengaitkannya dengan fenomena sosial, budaya, ekonomi, iptek dan seni dan lain-lain untuk-untuk mengembangkan kebudayaan dan peradaban Islam

Tujuan SKI diatas merupakan tujuan ideal yang harus mampu diterjemahkan guru dalam setiap proses pembelajarannya. Sayangnya, mayoritas guru SKI di madrasah menyakini bahwa satu-satunya cara mengajarkan SKI adalah dengan dongeng, bercerita, tanpa ada pilihan yang lebih variatif lagi. (PLPG UIN Malang,2012) Hal ini disebabkan tidak adanya pemetaan atau analisis materi SKI sebelum guru mengajarkannya. Pemetaan dan analisis yang kering tentu saja menjadikan metode pembelajaran yang dipilihjuga seadanya sehingga tujuan ideal pembelajaran SKI di sekolah belum tercapai.

\section{B. Memahami Sejarah sebagai Mother of Science}

Sejarah merupakan ratu atau ibu ilmu ilmu-ilmu sosial. Konotasi ibu dan ratu mengindikasikan bahwa sejarah merupakan ilmu yang yang sangat penting dan tidak boleh disepelekan. Sejarah berasal dari histoy yang diambil dari kata historia yang dalam bahasa Yunani berarti informasi atau penelitian yang ditujukan untuk memperoleh kebenaran. (Kochhar, 2008:1) berikut :

Kochahr pun merangkum beberapa definisi sejarah sebagai

a. Menurut Buchkhardt, sejarah merupakan catatan tentang suatu masa yang ditemukan dan dipandang bermanfaat oleh generasi dari zaman yang lain

b. Miller berpendapata bahwa sejarah adalah catatan perjalanan hidup manusia bagaikan samudra

c. Marc Bloch, sejarah adalah ilmu tentang manusia dalam lingkup 
Isti'anah Abubakar - Pengembangan Materi Sejarah ...

waktu

d. E.H. Carr, sejarah merupakan dialog tanpa akhir antara masa sekarang dan masa lampau

e. Pt.Nehru, sejarah merupakan kisah tentang perjuangan manusia sepanjang mas dalam menghadapi alam dan unsur-unsurnya

Beberapa pendapat diatas menunjukkan bahwa definis sejarah tidak satupun yang diterima secara universal mengingat cakupan makna yang terkandung di dalamnya sangat luas.

Sejarah juga berasal dari bahasa Arab yang berarti pohon. Ini memberikan gambaran adanya pertumbuhan peradaban manusia dengan istilah "pohon" yang tumbuh dari biji yang kecil menjadi pohon yang rindang dan berkesinambungan. ${ }^{1}$ Istilah pohon (شجرة) dalam Al Qur an terdapat dalam 18 surat (Fuad Abdul Baqi : 357) yaitu :

\begin{tabular}{|c|c|c|}
\hline No & Surat dan Ayat & Uraian \\
\hline & & 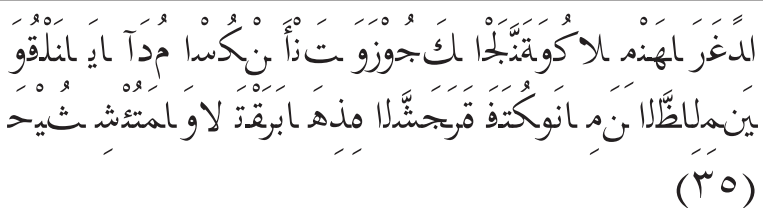 \\
\hline 1 & QS. $2: 35$ & $\begin{array}{l}\text { 35. Dan kami berfirman: "Hai Adam, } \\
\text { diamilah oleh kamu dan isterimu surga ini, } \\
\text { dan makanlah makanan-makanannya yang } \\
\text { banyak lagi baik dimana saja yang kamu } \\
\text { sukai, dan janganlah kamu dekati pohon } \\
\text { ini[37], yang menyebabkan kamu termasuk } \\
\text { orang-orang yang zalim. }\end{array}$ \\
\hline
\end{tabular}

${ }^{1}$ Ahmad Mansur Suryanegara, Menemukan Sejarah Wacana Pergerakan Islam di Nusantara, Mizan, Bandung, 1995, h. 20 
Isti'anah Abubakar - Pengembangan Materi Sejarah ...

\begin{tabular}{|c|c|c|}
\hline 2 & QS.7 : 19 & 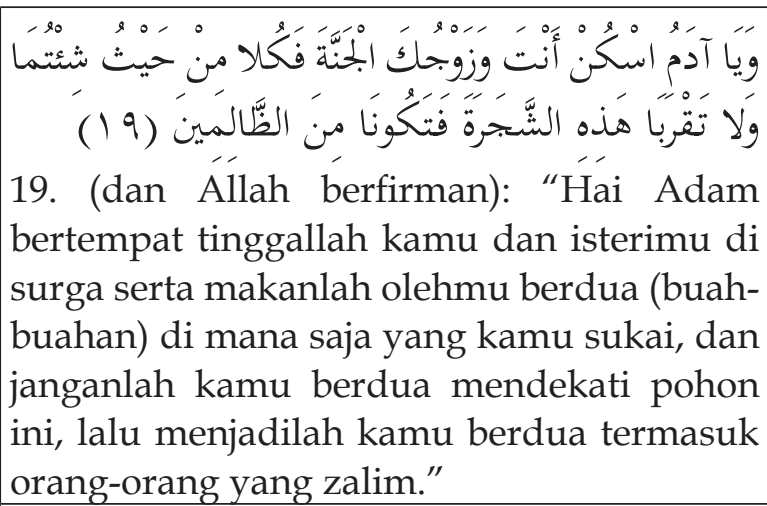 \\
\hline 3 & QS. 7: 20 & 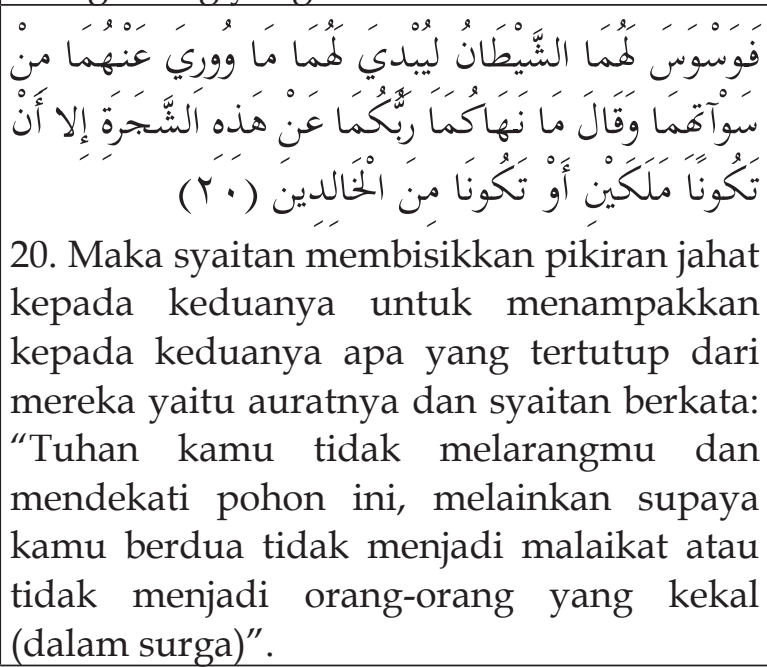 \\
\hline
\end{tabular}




\begin{tabular}{|c|c|c|}
\hline 4 & $\begin{array}{c}\text { QS.7: } 22 \\
\text { Ada } 2 \text { kata } \\
\text { sajarah }\end{array}$ & 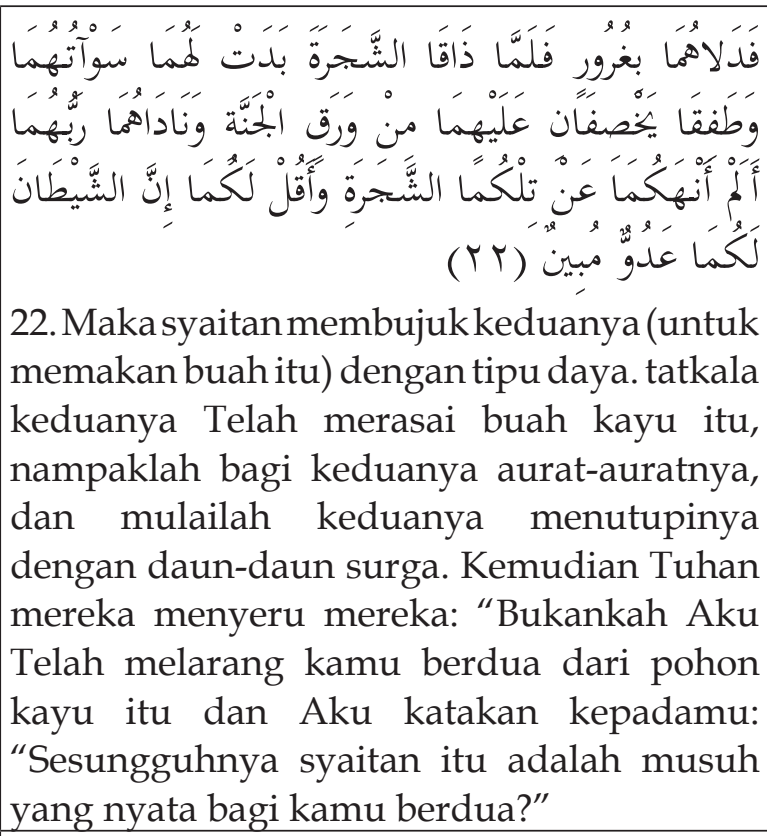 \\
\hline 5 & QS.14: 24 & 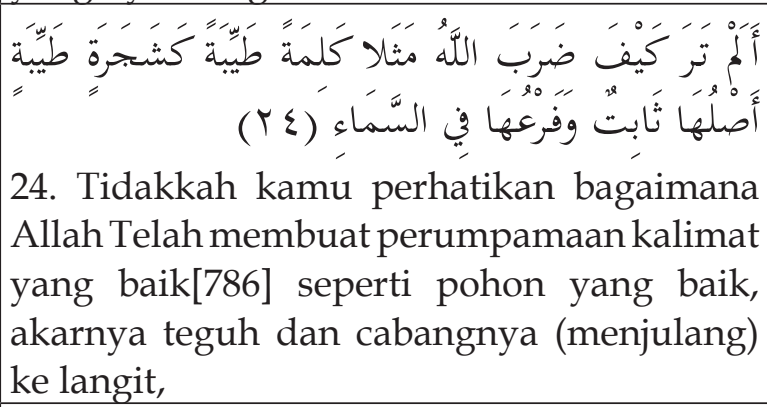 \\
\hline 6 & QS. 14: 26 & 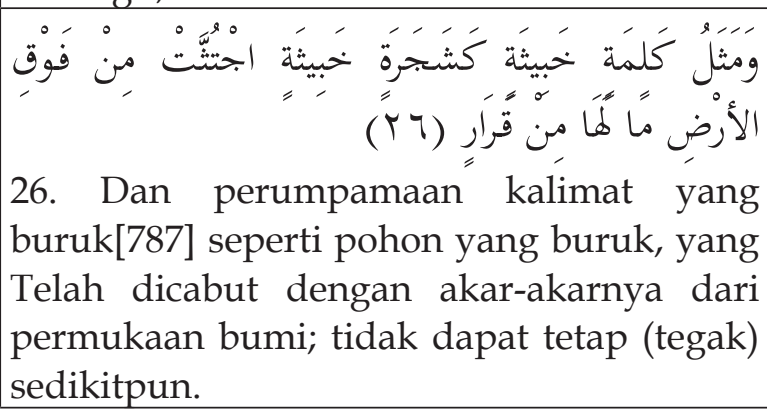 \\
\hline
\end{tabular}


Isti'anah Abubakar - Pengembangan Materi Sejarah ...

\begin{tabular}{|c|c|c|}
\hline 7 & QS. 17 : 60 & 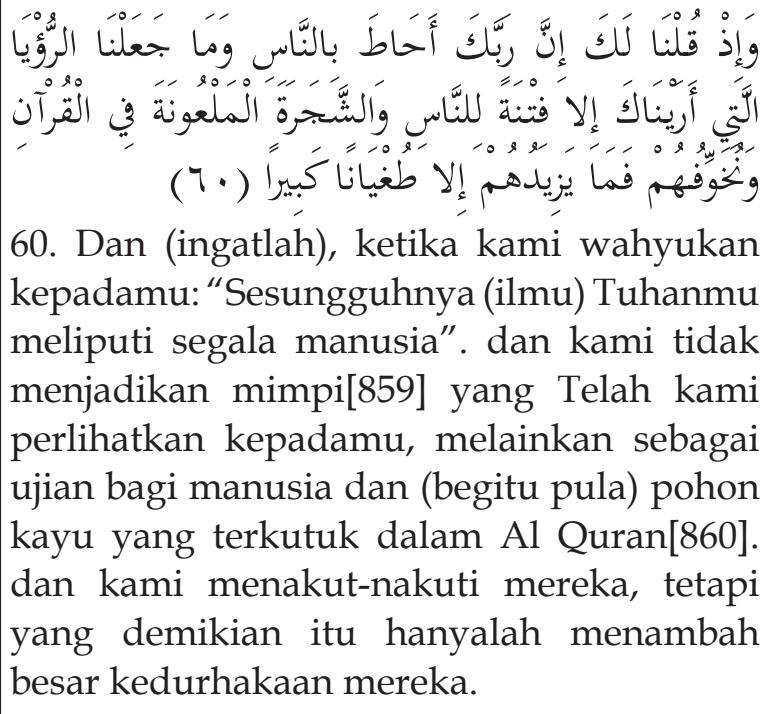 \\
\hline 8 & QS. $20: 120$ & 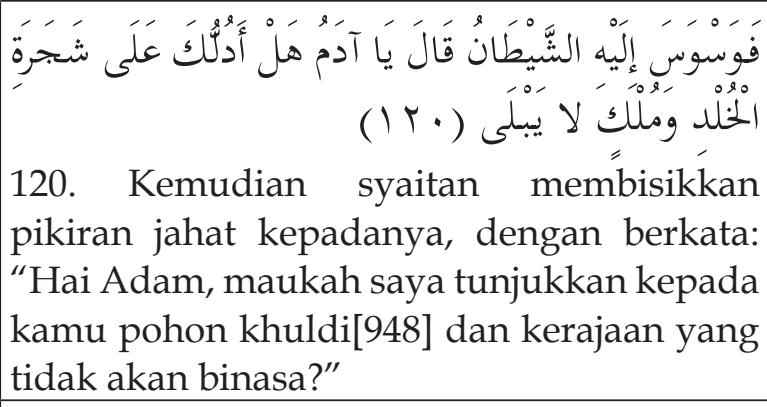 \\
\hline 9 & QS.23:20 & 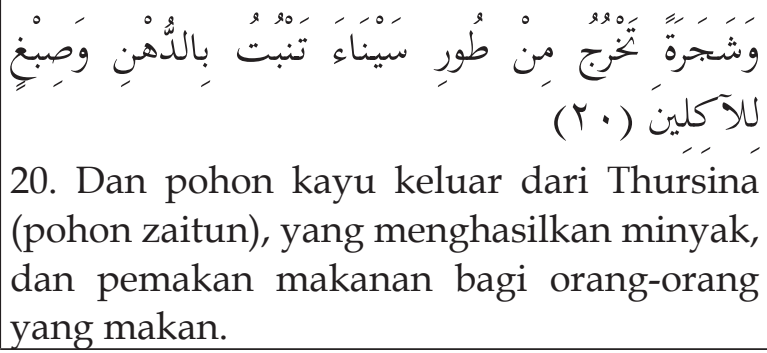 \\
\hline
\end{tabular}


Isti'anah Abubakar - Pengembangan Materi Sejarah ...

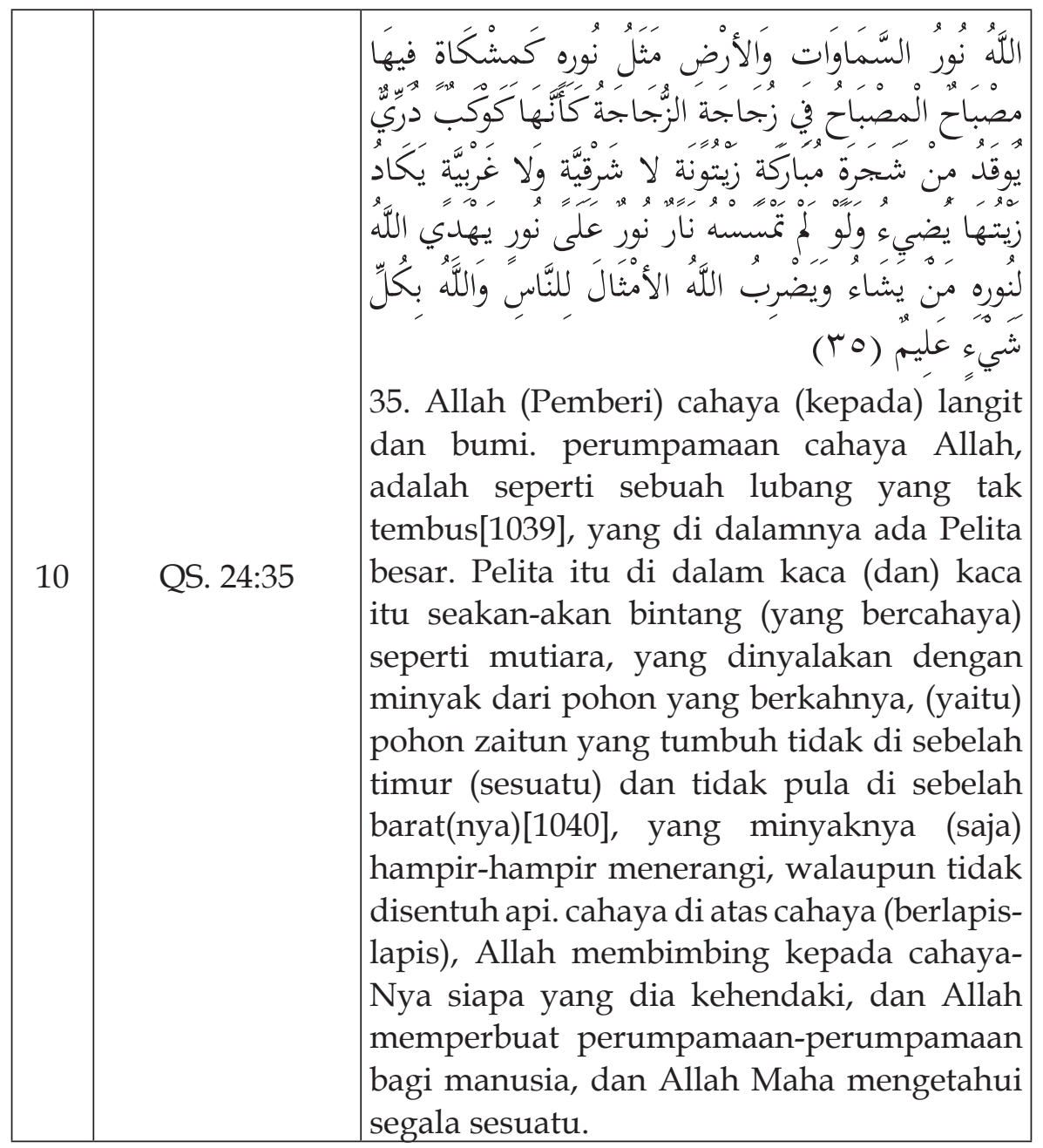


Isti'anah Abubakar - Pengembangan Materi Sejarah ...

\begin{tabular}{|c|c|c|}
\hline 11 & QS. $28: 30$ & 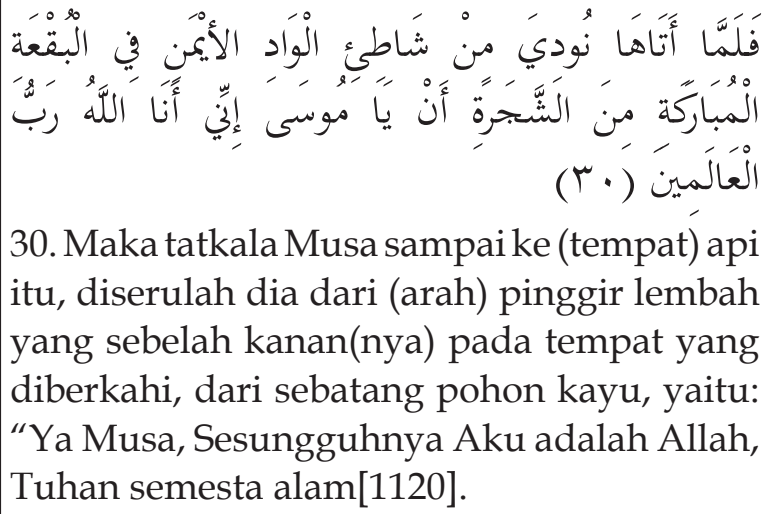 \\
\hline 12 & QS. 31:27 & 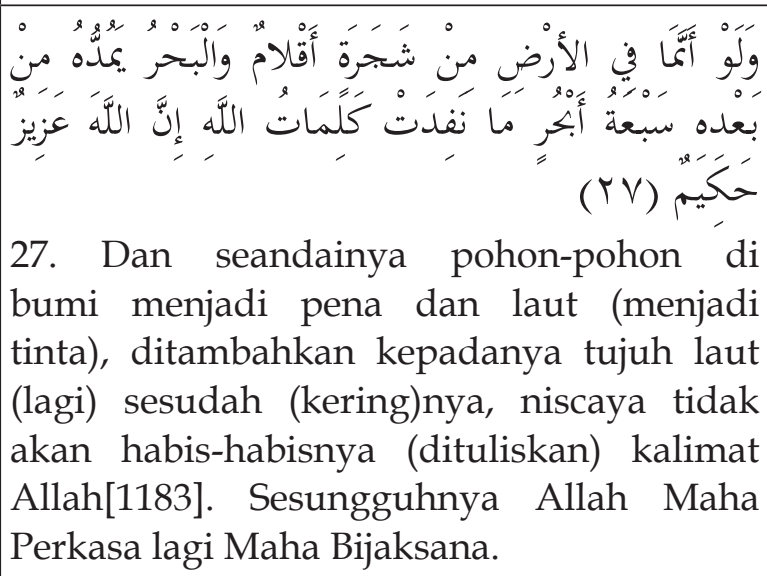 \\
\hline 13 & QS.37:62 & 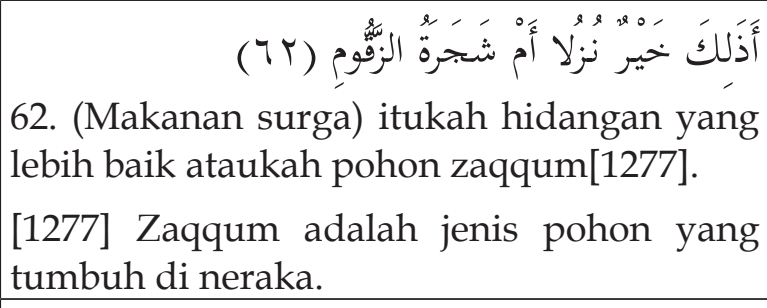 \\
\hline 14 & QS. 37:64 & 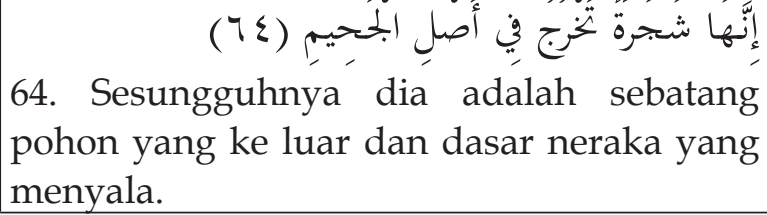 \\
\hline
\end{tabular}


Isti'anah Abubakar - Pengembangan Materi Sejarah ...

\begin{tabular}{|c|c|c|}
\hline 15 & QS. 37:146 & 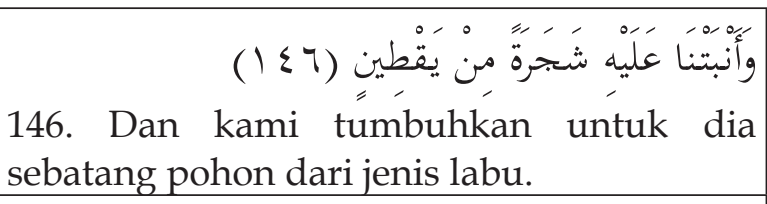 \\
\hline 16 & QS.44:43 & 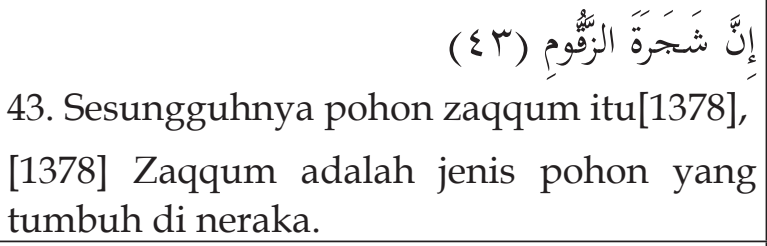 \\
\hline 17 & QS.48:18 & 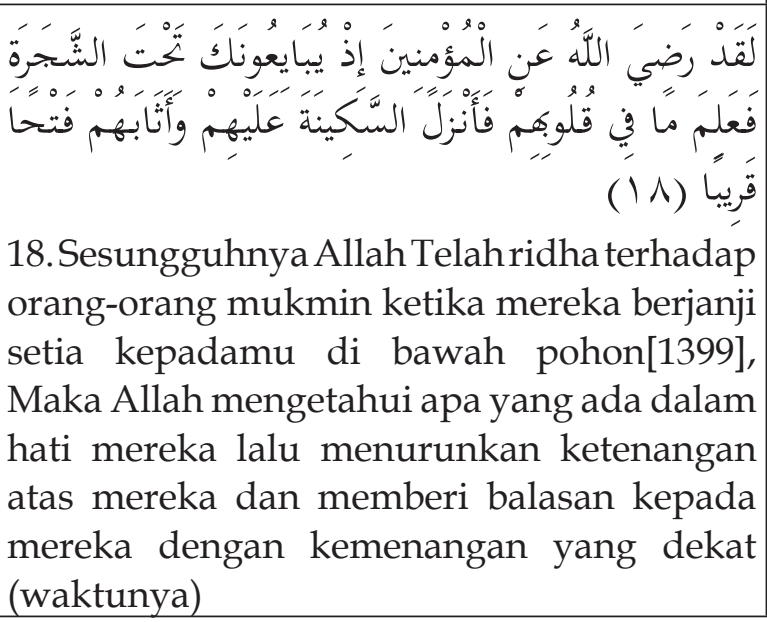 \\
\hline
\end{tabular}

Dari ayat-ayat di atas maka dapat dipetakan bahwa sejarah yang berarti pohon mengandung pengertian sebagai berikut:

a. Sejarah mengandung makna perubahan (change) dari langit ke bumi untuk menerima amanah sebagai khalifah Allah. Gambaran ini terlihat dalam QS. 2 :35; QS. $7: 10,22$

b. Sejarah merupakan peristiwa yang akan terus dalam peradaban manusia seperti digambarkan dalam QS. 28:30, dimana Musa harus berupaya keras untuk mencapai tempat tertinggi hanya untuk berjumpa denganNya

c. Sejarah adalah sebagai pelita yang dapat menerangi manusia dalam menjalani kehidupannya sesuai gambaran QS. 24:35

Bahasan di atas hampir sama dengan yang diungkapkan Kochar tentang hakekat sejarah(Kochhar, 2008:3-6) , yaitu (1) sejarah adalah ilmu tentang manusia, (2) sejarah mengkaji manusia dalam lingkup waktu, (3) sejarah mengkaji manusia dalam lingkup runag, (4) sejarah 
menjelaskan masa kini, (5) sejarah merupakan dialog antara peristiwa masa lampau dan perkembangan kemasa depan, (6) sejarahmerupakan cerita tentang perkembangan kesadaran manusia baik dalam aspek individual maupu kolektif, (7) kontinuitas dan keterkaitan adalah hak yang sangat penting dalam sejarah.

\section{Pembelajaran Sejarah : Konsep dan Karakteristik serta Ruang Lingkupnya}

Kompleksitas dan saratnya makna sejarah memerlukan pembelajaran yang juga bermakna. Pembelajaran identik dengan kegiatan yang dilakukan guru untuk mampu mendesain pengalaman belajar siswa sesuai dengan karakteristik siswa dan mata pelajarannya. Hal ini berarti bahwa, guru harus memahami betul apa yang harus diketahui, dilakukan dan akan menjadi (Kochhar, 2008 : 27) apa nantinya siswa tersebut dengan mata pelajaran yang diberikan itu.

1. Konsep dan Karakteristik Pembelajaran Sejarah

Terdapat 8 konsep pokok yang utama dalam pembelajaran sejarah yang diungkapkan Richard Green ( 2009:113) yaitu : waktu, situasi/peristiwasejarah dan karakteristiknya (pengertian akan periode tertentu), kontinuitas, perubahan, sebab, konsekuensi/akibat, interpretasi/sudut pandang, bukti sejarah. Adapun apa yang seyogyanya dipelajari dalam sejarah dapat dilihat di bawah ini:

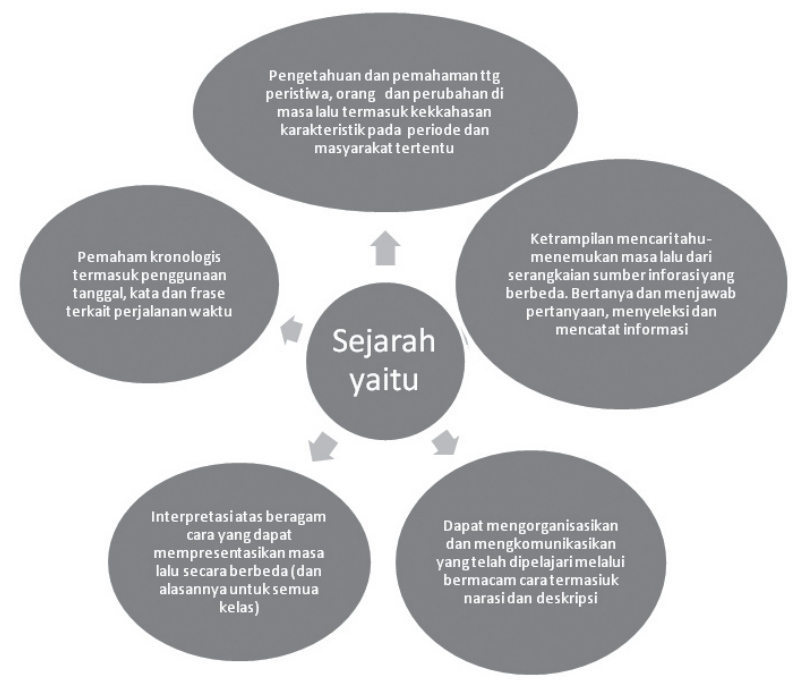

Madrasah, Vol. 4 No. 2 Januari - Juni 2012233 
Isti'anah Abubakar - Pengembangan Materi Sejarah ...

Adapun Kochhar (2008 :27) mengungkapkan bahwa sasaran umum pembelajaran sejarah sebagai berikut : mengembangkan pemahaman tentang diri sendiri ,memberi gambaran yang tepat tentang konsep waktu, ruang dan masyarakat, membuat masyarakat mampu mengevaluasi nilai-nilai dan hasil yang telah dicapai oleh generasinya,mengajarkan toleransi, menanamkan sikap intelektual, memperluas cakrawala intelektualitas, mengajarkan prinsip-prinsip moral, menanamkan orientasi ke masa depan, memberikan pelatihan mental Melatih siswa menangani isu-isu kontroversial, membantu mencarikan jalan keluar bagi berbagai masalah sosial dan perseorangan, memperkokoh nasionalisme, mengembangkan pemahaman internasional, mengembangkan ketrampilan-ketrampilan yang berguna. Konsep pokok dan sasaran umum pembelajaran sejarah ini sesuai dengan karakteristik PAI, yaitu :

\section{Tabel 1. Karakteristik PAI}

\begin{tabular}{|c|c|l|}
\hline No & Mata Pelajaran & \multicolumn{1}{|c|}{ Karakteristik } \\
\hline 1 & Al Quran & $\begin{array}{l}\text { Transenden, Qath'i, informatif, statis, } \\
\text { Interpretable, dll }\end{array}$ \\
\hline 2 & Aqidah & $\begin{array}{l}\text { Doktriner, dogmatis, apologis, rasional- } \\
\text { argumentatif, statis, dll }\end{array}$ \\
\hline 3 & Akhlak & $\begin{array}{l}\text { Substantif, qath'i, stabil, spriritualis, } \\
\text { Continuity, dll }\end{array}$ \\
\hline 4 & Ibadah & $\begin{array}{l}\text { Fleksibel, dinamis, zhanni, utility, Change, } \\
\text { dll. }\end{array}$ \\
\hline 5 & Tarikh & $\begin{array}{l}\text { Transformatif, informatif, dinamis, kreatif, } \\
\text { inovatif, dll }\end{array}$ \\
\hline
\end{tabular}

Sesuai karakteristik diatas, maka SKI - tarikh - lebih berkarakteristik transformatif, informatif, dinamis, kreatif dan inovatif, kelima karaktersitik tersebut sesuai dengan konsep, hakaket sejarah dalam pembahasan sebelumnya. Ini menunjukkan perlunya upaya dalam penelaahan materi sehingga karakteristik tarikh dapat dipenuhi yang kemudian diperkuat dengan pemilihan metode yang tepat dalam proses pembelajarannya.

\section{Ruang Lingkup Kajian dan Penekanan SKI sebagai Mata Pelajaran}

Sesuai dengan hakekat, konsep dan sasaran umum serta karak- 
teristik sejarah di atas, maka ruang lingkup kajian SKI adalah tentang pertumbuhan dan perkembangan agama Islam dari awalnya sampai zaman sekarang sehingga peserta didik dapat mengenal dan meneladani tokoh-tokoh Islam serta mencintai agama Islam (Kemenag RI, 2010 :16). Setidaknya ada 2 hal yang dapat dipahami dari lingkup kajian SKI tersebut, pertama, content materinya terkait pertumbuhan dan perkembangan agam Islam, kedua, tujuannya adalah menjadikan peserta didik mengenal dan semakin mencintai Islam sebagai agamanya. Realita pembelajaran selama ini guru lebih terfokus pada content materinya yang tersebar dalam silabus sebagai rencana pembelajaran, sedangkan pembentukan sikap terkait dengan tujuan pembelajaran SKI belum banyak disentuh dan dibelajarkan guru kepada peserta didik. Inilah yang menjadikan guru dan siswa masih berpandangan bahwa SKI adalah dongeng dan kisah saja. Ini sesuai dengan penekanan kemampuan yang dibebankan pada SKI (Kemeng RI, 2010 : 17) yaitu kemampuan untuk mengambil ibrah dari peristiwa-peristiwa bersejarah (Islam), meneladani tokoh-tokoh berprestasi dan mengaitkannya dengan fenomena sosial, budaya, politik, ekonomi, iptek dan seni dan lain-lain untuk mengembangkan kebudayaan dan peradaban Islam.

\section{Pemetaan Materi dan Pemilihan Strategi Pembelajaran SKI ( Materi SKI untuk kelas 1 MTs )}

Materi merupakan pengetahuan, ketrampilan dan sikap yang harus dikuasai peserta didik dalam rangka memenuhi standar kompetensi yang ditetapkan. Materi menempati posisi strategis terkait content yang harus diberikan kepada peserta didik. Untuk itu diperlukan penelaahan, pengkajian agar materi dapat dicerna oleh peserta didik dengan baik. Adapun klasifikasi pemetaan materi sebagai berikut :(Tim Dosen Fakultas Tarbiyah, 2010 :162)

1. Fakta/Informatif, segala hal yang berwujud kenyataan dan kebenaran, meliputi nama-nama objek, peristiwa sejarah , lambang, nama tempat. Contoh : Peristiwa terjadinya perang Badr

2. Konsep, segala hal yang berwujud pengertian-pengertian baru yang bisa timbul sebagai hasil pemikiran, meliputi definisi, pengertian, ciri khusus. Contoh: pengertian SKI

3. Prosedur, merupakan langkah-langkah sistematis atau berurutan 
Isti'anah Abubakar - Pengembangan Materi Sejarah ...

dalam mengerjakan suatu aktivitas dan kronologi suatu sistem. Artinya, tidak boleh menyebutkan suatu aktivitas dengan terbalikbalik, jika terjadi maka akan menyebabkan suatu aktivitas ataupun peristiwa menjadi suatu hal yang salah. Contoh : menjelaskan sejarah Nabi Muhammad mulai kecil sampai meninggal.

4. Sikap atau nilai, merupakan hasil belajar aspek sikap, dalam konteks ini maka lebih pada timbulnya kemampuan peserta didik untuk mengambil ibrah terhadap semua peristiwa sejarah yang ada sehingga sikap didik terbentuk melalui peristiwa sejarah Islam.

5. Ketrampilan, suatu unjuk kerja atau kemampuan yang dimiliki oleh siswa yang mampu diamati dan diukur. Contoh : Kemampuan siswa dalam mempresentasikan sejarah Nabi Muhammad masa Makkah

Perlu diingat, pembelajaran yang bermakna dengan pengalaman belajar yang kaya merupakan bentukan dari beberapa analisis atau pengkajian materi di atas yang saling menguatkan. Berdasarkan pada Standar Kompetensi dan kompetensi dasar yang ada maka akan terbentuk analisis materi yang sifatnya primer dan sekunder. Primer berarti bahwa tidak boleh ditinggalkan dan harus dipastikan bahwa itu dikuasai peserta didik, adapun sekunder lebih berarti penguat atau suplemen untuk memberikan 3 domain belajar yang hgarus dicapai di setiap mata pelajaran.

Untuk lebih mengkongkritkan pembahasan di atas berikut ini tahapan yang harus dilalui guru untuk dapat menghadirkan pembelajaran sejarah yang bermakna. Sebagai contoh akan dipaparkan silabus pembelajaran SKI kelas 1 (semester 1 dan 2 ) untuk siswa Madrasah Tsanawiyah

Tabel 2. Analisis Materi SKI kelas 1

\begin{tabular}{|c|c|c|}
\hline No & $\begin{array}{c}\text { Standar Kompertensi - Kompetensi } \\
\text { Dasar }\end{array}$ & Analisis Materinya \\
\hline 1 & \multicolumn{2}{|l|}{ Memahami Sejarah kebudayaan Islam : } \\
\hline & Pengertian Sejarah kebudayaan Islam & \multirow{3}{*}{$\begin{array}{l}\text { Primer: Konsep } \\
\text { Sekunder : Fakta, } \\
\text { Sikap, Ketrampilan }\end{array}$} \\
\hline & Tujuan dan Manfaat mempelajari SKI & \\
\hline & Mengidentifikasi bentuk/wujud SKI & \\
\hline 2 & \multicolumn{2}{|c|}{ Memahami Sejarah nabi Muhammad SAW Periode Makkah } \\
\hline
\end{tabular}


Isti'anah Abubakar - Pengembangan Materi Sejarah ...

\begin{tabular}{|c|c|c|}
\hline & $\begin{array}{l}\text { 1) Misi Nabi SAW bagi alam semesta, } \\
\text { pembawa kedamaian, kesejahteraan, } \\
\text { kemajuan }\end{array}$ & $\begin{array}{l}\text { Primer : Fakta } \\
\text { Sekunder : Konsep, } \\
\text { Sikap, Ketrampilan }\end{array}$ \\
\hline & $\begin{array}{l}\text { (2) Mengambil ibrah dari misi Nabi } \\
\text { SAW bagi alam semesta, pembawa } \\
\text { kedamaian, kesejahteraan, kemajuan }\end{array}$ & $\begin{array}{l}\text { Primer : Sikap } \\
\text { Sekunder : Fakta } \\
\text { dan Ketrampilan }\end{array}$ \\
\hline & $\begin{array}{l}\text { 3) Meneladani perjuangan Nabi } \\
\text { SAW dan Sahabat dlm menghadapi } \\
\text { masyarakat Makkah }\end{array}$ & $\begin{array}{l}\text { Primer : Sikap } \\
\text { Sekunder : Fakta } \\
\text { dan Ketrampilan }\end{array}$ \\
\hline 3 & \multicolumn{2}{|c|}{ Memahami Sejarah Nabi SAW periode Madinah } \\
\hline & $\begin{array}{l}\text { (1) Sejarah Nabi SAW dalam } \\
\text { membangun masyarakat melalui } \\
\text { kegiatan ekonomi dan perdagangan }\end{array}$ & $\begin{array}{l}\text { Primer : Fakta } \\
\text { Sekunder : } \\
\text { Konsep, Sikap dan } \\
\text { Ketrampilan }\end{array}$ \\
\hline & $\begin{array}{l}\text { (2) mengambil ibrah dari misi Nabi } \\
\text { SAW dalam membangun masyarakat } \\
\text { melalui kegiatan ekonomi dan } \\
\text { perdagangan }\end{array}$ & $\begin{array}{l}\text { Primer : Sikap } \\
\text { Sekunder : Fakta, } \\
\text { Ketrampilan }\end{array}$ \\
\hline & $\begin{array}{l}\text { (3) meneladani semangat perjuangan } \\
\text { Nabi dan sahabat di Madinah }\end{array}$ & $\begin{array}{l}\text { Primer : Sikap } \\
\text { Sekunder: Fakta, } \\
\text { Ketrampilan }\end{array}$ \\
\hline 4 & \multicolumn{2}{|c|}{$\begin{array}{l}\text { Memahami sejarah Perkembangan Islam pada masa } \\
\text { Khulafaur Rasyidin }\end{array}$} \\
\hline & $\begin{array}{l}\text { (1) prestasi yang dicapai Khulafaur } \\
\text { Rasyidin }\end{array}$ & $\begin{array}{l}\text { Primer : Fakta } \\
\text { Sekunder : Konsep, } \\
\text { Sikap, Ketrampilan }\end{array}$ \\
\hline & $\begin{array}{l}\text { (2)mengambil ibrah dari prestasi yang } \\
\text { dicapai Khulafaur Rasyidin }\end{array}$ & $\begin{array}{l}\text { Primer : Sikap } \\
\text { Sekunder : } \\
\text { Fakta, Konsep, } \\
\text { Ketrampilan }\end{array}$ \\
\hline & $\begin{array}{l}\text { (3) Meneladani gaya kepemimpinan } \\
\text { Khulafaur Rasyidin }\end{array}$ & $\begin{array}{l}\text { Primer : Sikap } \\
\text { Sekunder : } \\
\text { Fakta,Konsep, } \\
\text { Ketrampilan }\end{array}$ \\
\hline 5 & \multicolumn{2}{|c|}{ Memahami perkembangan Islam Masa Umayyah } \\
\hline
\end{tabular}


Isti'anah Abubakar - Pengembangan Materi Sejarah ...

\begin{tabular}{|l|l|l|}
\hline (1) sejarah berdirinya & $\begin{array}{l}\text { Primer : Fakta } \\
\text { Sekunder : } \\
\text { Konsep,Prosedur, } \\
\text { Ketrampilan }\end{array}$ \\
\hline & $\begin{array}{l}\text { (2) perkembangan kebudayaan/ } \\
\text { peradabannya }\end{array}$ & $\begin{array}{l}\text { Primer : Fakta } \\
\text { Sekunder : Konsep, } \\
\text { Sikap, Ketrampilan }\end{array}$ \\
\hline & $\begin{array}{l}\text { (3)identifikasi tokoh muslim dan } \\
\text { perannya dalam kebudayaan.peradaban } \\
\text { Umayyah }\end{array}$ & $\begin{array}{l}\text { Primer : Fakta } \\
\text { Sekunder : } \\
\text { Konsep,Sikap, } \\
\text { Ketrampilan }\end{array}$ \\
\hline $\begin{array}{l}\text { (4) Mengambil ibrah dari kebudayaan/ } \\
\text { peradaban masa Umayyah untuk masa } \\
\text { kini dan masa datang }\end{array}$ & $\begin{array}{l}\text { Primer : Sikap } \\
\text { Sekunder : } \\
\text { Fakta,Konsep, } \\
\text { Ketrampilan }\end{array}$ \\
\hline
\end{tabular}

Berdasarkan contoh analisis materi SKI kelas 1 di atas, maka dapatlah diperoleh kesimpulan bahwa materi SKI lebih didominasi oleh komponen fakta, sikap dan konsep. Artinya, materi SKI lebih didominasi pada aktivitas yang bisa dilakukan siswa terkait materimateri yang harus dicari berdasarkan fakta sejarah yang bisa diperoleh melalui konsep atau pendapat para sejarawan sehingga mampu membentuk sikap atau perilaku peserta didik nantinya. Ini semakin menunjukkan bahwa pembelajaran sejarah tidak harus didominasi oleh dongeng atau kisah yang diberikan oleh guru, tapi akan lebih maksimal bila peserta didik diberikan kesempatan dan difasilitasi untuk mencari sendiri fakta sejarah yang dikehendaki.

Berangkat dari analisis materi di atas dengan berdasarkan klasifikasi materinya, maka metode pembelajaran yang dapat digunakan sebagai berikut :

Tabel 3. Alternatif Metode Pembelajarannya

\begin{tabular}{|c|l|l|}
\hline No & Klasifikasi Materi & \multicolumn{1}{c|}{ Metode Pembelajaran } \\
\hline 1. & Fakta - Informatif & $\begin{array}{l}\text { Information Search, Reading } \\
\text { Guide, Every One is Teacher Here, } \\
\text { mengurutkan cerita, peta konsep, mind } \\
\text { mapping, dll }\end{array}$ \\
\hline 2. & Konsep & Reading Guide, Kronologi, dll \\
\hline 3. & Sikap & Story Telling,dll \\
\hline
\end{tabular}


Isti'anah Abubakar - Pengembangan Materi Sejarah ...

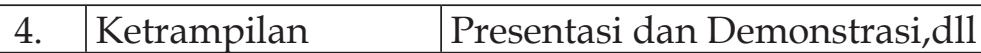

Berikut ini akan dipaparkan langkah-langkah kongkrit yang dapat digunakan dalam membelajarkan SKI.

Tabel 4. Contoh Penjabaran Materi dan Pembelajaran Sejarah

\begin{tabular}{|c|c|c|}
\hline 1. & Materi & $\begin{array}{l}\text { Misi Nabi SAW bagi alam semesta, } \\
\text { pembawa kedamaian, kesejahteraan, } \\
\text { kemajuan }\end{array}$ \\
\hline 2. & $\begin{array}{l}\text { Materi yang } \\
\text { harus dikuasai }\end{array}$ & $\begin{array}{l}\text { Berdasarkan } 5 \mathrm{~W} \text { dan } 1 \mathrm{H} \text {, yaitu: } \\
\text { What, apa yang dimaksud dengan misi } \\
\text { Nabi SAW sebagai alam semesta, pembawa } \\
\text { kedamaian, kesejahteraan dan kemajuan } \\
\text { Who, Siapa yang ada dalam potongan } \\
\text { cerita tersebut } \\
\text { When,kapankah peristiwa dalam potongan } \\
\text { cerita itu terjadi } \\
\text { Where, Dimanakah peristiwa itu terjadi } \\
\text { Why, Mengapa bisa terjadi peristiwa } \\
\text { tersebut (jika ada ) } \\
\text { How, Bagaimanakah peristiwa detailnya } \\
\text { dan apakah peristiwa yang selanjutnya }\end{array}$ \\
\hline 3. & $\begin{array}{l}\text { Media } \\
\text { yang perlu } \\
\text { disediakan }\end{array}$ & $\begin{array}{l}\text { Peta } \\
\text { Potongan-potongan cerita } \\
\text { Mengurutkan cerita }\end{array}$ \\
\hline 4. & $\begin{array}{l}\text { Klasifikasi } \\
\text { Materi }\end{array}$ & $\begin{array}{l}\text { Primer : Fakta } \\
\text { Sekunder : Konsep,Prosedur, Ketrampilan }\end{array}$ \\
\hline
\end{tabular}




\begin{tabular}{|l|l|l|}
\hline 4. & $\begin{array}{l}\text { Guru menyiapkan terlebih dahulu } \\
\text { potongan cerita terkait Misi Nabi } \\
\text { Muhammad saw atau guru bisa } \\
\text { menjabarkan materinya bterlebih dahulu } \\
\text { (contoh media ada di bawah tabel) } \\
\text { Siswa diberikan garis-garis besar cerita } \\
\text { yang telah dipotong-potong } \\
\text { Kemudian siswa diminta untuk mengambil } \\
\text { potongan cerita yang dimaksud, untuk } \\
\text { kemudian menjawab pertanyaan berbasis 5 } \\
\text { W dan 1 H } \\
\text { Kemudian siswa diminta untuk } \\
\text { menceritakan secara detailnya dan jika } \\
\text { perlu mendemostrasikannya }\end{array}$ \\
\hline
\end{tabular}

Contoh Media yang digunakan (diambil dariTim Gema Insani, 2010 )

\begin{tabular}{|c|l|l|}
\hline No & \multicolumn{1}{|c|}{ Potongan Cerita } & \multicolumn{1}{c|}{ Keterangan } \\
\hline 1. & $\begin{array}{l}\text { Wahai Nabi Muhammad. } \\
\text { Orang-orang Quraisy } \\
\text { menawarkan kepadamu } \\
\text { harta yang banyak dan } \\
\text { mereka menuruti segala } \\
\text { keinginanmu asalkan } \\
\text { kamu tidak lagi mengajak } \\
\text { manusia menyembah Allah }\end{array}$ & $\begin{array}{l}\text { Yang bisa ditanyakan: } \\
\text { Siapakah yang berbicara } \\
\text { Apa Respon Nabi SAW } \\
\text { Mengapa pamannya } \\
\text { mengatakan hal tersebut }\end{array}$ \\
\hline 2. & $\begin{array}{l}\text { Yang bisa ditanyakan : } \\
\text { Peristiwa apakah itu } \\
\text { Apa yang kamu ketahui dari } \\
\text { kedatangannya dan } \\
\text { di langit kedua beliau } \\
\text { disambut Nabi Isa }\end{array}$ & $\begin{array}{l}\text { Meristiwa tersebut } \\
\text { Mengapa terjadi peristiwa itu } \\
\text { terjadi } \\
\text { Apa yang didapat dari peristiwa } \\
\text { itu? } \\
\text { Bagaimana respon masyarakat } \\
\text { terhada peristiwa tersebut }\end{array}$ \\
\hline
\end{tabular}


Isti'anah Abubakar - Pengembangan Materi Sejarah ...

\begin{tabular}{|c|c|c|}
\hline 3. & $\begin{array}{l}\text { Ka'bah selalu dijaga oleh } \\
\text { Allah. Tidak ada yang bisa } \\
\text { menghancurkannya }\end{array}$ & $\begin{array}{l}\text { Yang bisa ditanyakan: } \\
\text { Pada peristiwa apakah itu } \\
\text { terjadi? } \\
\text { Siapakah yang mengatakan itu? } \\
\text { Terkenal dengan apakah } \\
\text { peristiwa itu? } \\
\text { Apa surat dalam Al Qur an yang } \\
\text { menceritakan peristiwa tersebut } \\
?\end{array}$ \\
\hline 4. & $\begin{array}{l}\text { Kalau kalian sepakat } \\
\text {, bagaimana kalo kita } \\
\text { serahkan keputusan ini } \\
\text { kepada orang yang pertama } \\
\text { kali masuk ke Baitullah....... } \\
\text { Semua kepala suku } \\
\text { mengangkat Hajar Aswad. } \\
\text { Mereka amat gembira } \\
\text { mendapat kehormatan } \\
\text { untuk meletakkan batu } \\
\text { mulia itu ke tempatnya. } \\
\text { Maka hilanglah rasa } \\
\text { dendam dan benci di hati } \\
\text { mereka. Semua kembali } \\
\text { bersahabat dan bersaudara } \\
\text { dengan tulus }\end{array}$ & $\begin{array}{l}\text { Yang bisa ditanyakan : } \\
\text { Peristiwa apakah itu? } \\
\text { Pada umur berapa Nabi SAW } \\
\text { pada waktu itu? } \\
\text { Bisakah kamu } \\
\text { mendemosntrasikannya? }\end{array}$ \\
\hline
\end{tabular}

Potongan cerita di atas bisa ditambah atau dikurangi sesuai dengan kemampuan guru dan karakteristik siswa. Langkah ini akan berjalan baik, jika siswa terlebih dahulu membaca referensi terkait atau guru terlebih dahulu memberikan penjelasan segmen-segmen terkait. Kemudian siswa dibagi menjadi beberapa kelompok, satu kelompok ditigaskan untuk mengurutkan cerita pasca penjelasan, sementara kelompok-kelompok siswa yang lain diminta untuk mengungkapkan persitiwa dan menjawab pertanyaan-pertanyaan tersebut. Jika telah selesai, maka guru akan meminta salah satu siswa untuk menceritkan kembali sesuai dengan urutan ceritanya. Kegiatan di atas merupakan salah satu kegiatan yang mampu mengaktifkan siswa seperti yang telah penulis lakukan pada praktek pembelajaran SKI dalam matakuliah SKI 1. 
Istianah Abubakar - Pengembangan Materi Sejarah ...

\section{E. Penutup}

Sejarah sebagai ratunya ilmu haruslah selalu dikaji dan diteguhkan komitmen pembelajarannya. Salah satu hal yang bisa dilakukan adalah membiasakan mengkaji, menelaah dan menyiapkan segala hal yang diperlukan pra proses pembelajaran. Pemahaman akan hakekat sejarah, konsep pembelajarannya dan ketepatan serta kepiawaian dalam menelaah materi akan mempengaruhi bermakna tidaknya pembelajaran.

\section{F. DAFTAR PUSTAKA}

Green, Richard, Brain Power SD, Aktivitas, Permainan dan Ide Praktis Belajar Ilmu Sosial, Pen, Herlina, Erlangga, 2009

Kemenag RI, Modul Pengembangan Pendidikan Agama Islam di Sekolah, Direktorat Pendidikan Islam, Jakarta, 2010

Kochhar, Teaching History, pen, Purwanta, Pembelajaran Sejarah, Grasindo, Jakarta, 2008

Tim Dosen Fakultas Tarbiyah UIN Maliki Malang, Materi PLPG Edisi Revisi, UIN Press, Malang, 2010

Tim Gema Insani, 20 Kisah Teladan, Gema Insani, 2010

Mahasiswa IPS, Persepsi Mahasiswa tentang Sejarah Peradaban Islam, hasil observasi - tugas UAS, tidak dipublikasikan, 2010

Mahasiswa PAI, Pembelajaran SKI di Madrasah Tsanawiyah, hasil observasi -tugas UTS dan UAS, tidak dipublikasikan, 2012 